\title{
The effect of wind- soil- structure interaction on the longitudinal response of high-rise buildings
}

\author{
Professor Dr. Sorush Niknamian \\ Board Member of Weston A Price Foundation, Washington DC, USA \\ Wmail: so.niknamian@gmail.com
}

\begin{abstract}
In this work, the modelling of the wind impact on the standard tall building of CAARC (Commonwealth Advisory Aeronautical Council), which is placed on a surface spread footing, is done numerically utilizing the ABAQUS program. The wind is demonstrated as an exponential way in the boundary layer of the atmosphere. Then, stream turbulence is modeled by the ILES technique and a cosimulation is accepted to exchange non-uniform loads from fluid to structural nodes. Damping of the structure is controlled by the Rayleigh strategy. Mechanical reaction of the footing-soil framework is modeled utilizing direct strategy. Infinite boundary conditions have been added to the numerical model for the simulation of free boundaries, and reasonable contact elements for sliding and separating between subsurface components are considered. Finally, fluid solutions and structural reactions are compared with the mean and root mean squares of experimental estimations on an extensive range of reduced speeds. Numerical results for the framework of soil-structure systems were compared with base conditions without association of soil-structure interaction. It is concluded that dynamic properties and reactions of the building influence soil-structure interaction and accordingly the planners should consider these parameters keeping in mind to guarantee the practical designing.
\end{abstract}

Keywords: High-rise buildings; interaction; flow turbulence; direct method; aero-dynamic; aero-elastic.

\section{Introduction}

With the advances in materials and development techniques, new tall structures are constructed with light weight and low damping. In this way, tall structures are sensitive to oscillations due to non-uniform wind loads. One of the most essential fields in Computational Fluid Dynamics (CFD) is Computational Wind Engineering (CWE), in that extraordinary numerical modelling is intended to model the impacts of wind on urban structures, for example, buildings. The determination of these impacts has generally been carried out utilizing empirical methods created in wind tunnels, in which the CAARC tall structure is normally utilized for verifying of empirical procedures.

Wardlaw and Moss (1970) firstly proposed standard modeling characteristics for wind tunnel investigations and aerodynamic features of structures, in that a basic CAARC building model was offered. A few experimental estimations were completed on the CAARC building model amid the 1970-1975 period after the work of Wardlaw and Moss. Utilizing this information, Melbourne (1980) gave a total correlation of the results of the CAARC building, containing estimations of pressure coefficients and dynamic reactions got at six research labs. Whitbread (1975) inferred aerodynamic forces and moments of CAARC stiff model, Blackmore (1985) utilized a flexible model to assess the dynamic reaction of structures exposed to mighty winds. Aero-elastic examinations on the CAARC building utilizing a 1:1000 scale model directed by Tanaka and Lawen (1986), Milford and Goliger (1988) completed a various experiments to research the impacts of wind tunnel methods in design of the building, Kwok (1988) analyzed the impacts of the wind-actuated response after eliminating the corners of the building. Base force and moments of a CAARC building model exposed to various wind attack angle were estimated utilizing the boundary layer and uniform streams by obasaju (1992). Thepmongkorn et al. (1999) surveyed the response of tall structures under the wind, utilizing flexible model, by assessing the mechanisms of wind impact and neighboring structures and eccentricity. Tang and kwok (2004) performed the interference impacts through a several wind tunnel tests on the CAARC building utilizing the novel flexible model with three degree of freedom and jointed torsionaltransitional motions. Research on longitudinal wind reaction of tall structures modeled in wind tunnel downbursts is reported by Chen and Letchford (2004).

Numerical research on aerodynamic schemes has been completed from the 1980s. Hirt et al presented one of the principal works regarding numerical modelling of the wind impact on the bluff objects. (1978). In this work, a model is proposed based on finite difference method and used for some aerodynamic features of bluff bodies. Hanson et al. (1986) and Summers et al. (1986) can be thought as the principal authors to model aerodynamic features of the building numerically. In this work, a computer modelling of wind stream around building models of various setups has been compared with wind tunnel tests. Some interesting discourses 
about the utilization of CWE turbulence models might be found in the articles by Murakami (1993). It can be inferred that utilizing LES (large eddy Simulation) delivers more precise outcomes than k- $\varepsilon$ models regardless of the expansive volume of computational cost and memory. Selvam (1992), Mochida et al. (1993), He and Song (1997), are several researchers who inspected numerically building of TTU. A further numerical investigation of urban wind conditions was directed by Stathopoulos and Baskaran (1996), in which a building model situated in the downtown zone of Montreal, Canada was examined. Haung et al. (2007) lately performed an aerodynamic investigation of the CAARC building model utilizing numerical method. The aerodynamic coefficient and streamlines near the building are resolved utilizing the CFD program.

In ordinary engineering, tall structures are frequently intended to have fixed footing, subsequently disregarding the soil-structure interaction (SSI). Indeed, soil deformability changes the dynamic attributes of the system in terms of normal periods as expressed by Gazetas (1997).

Soil-structure frameworks can be grouped into two classes: one direct technique and the other sub-structure technique. The most widely recognized approach to catch the impacts of SSI is to demonstrate a soil framework with an arrangement of visco-elastic components, one for every degree of freedom, whose stiffness and damping are characterized by identical springs and dampers, for instance refer to Harte et al. (2012). At times, this approach could be incorrect, since there is no admissible association between various degrees of freedom and non-elastic reaction because of plastic deformation may happen in the soil even at moderately low loads. Lately, various and more exact techniques have been introduced to address SSI impacts, for instance see Kausel (2010). A totally different and intense approach depends on the utilization of the finite element method to set up an exact model of the soil framework in the near field limited by dummy boundaries. In the near field, soil can be depicted by nonlinear elastic or completely non-elastic models that can model the soil attributes under powerful cyclic loading conditions, for instance see Halabian (2002). Albeit numerous uses of SSI models for structures that are influenced by seismic tremor are found in writings, just a couple of studies have been done for the wind-vibrating structures. Some of these projects addresses straight thin structures (e.g., wind turbines and reception apparatuses), and tall structures outfitted with control devices by Liu et al. (2008). In spite of the fact that the importance of considering SSI in windreacted structures is clear, as shown in Tnag et al. (2013) just the traditional strategy of the impedance coefficients for determining the stiffness and damping coefficients of springs and dampers representing the structure-soil framework is utilized.

In this paper, aero-dynamic and aero-elastic investigations are carried out on the CAARC building model numerically, while the numerical information for the structures of the CWE is extremely inadequate. In the numerical model embraced in this paper, Abaqus/CFD is utilized to solve stream representing equations, which is depicted kinetically utilizing the exact Lagrangian-Eulerian equation. ILES is utilized for turbulence demonstrating. The condition of structural movement in the time zone is solved utilizing Abaqus/Standard. Nonlinear geometric assumption is utilized in this work. A coupling plan is admitted for the interaction of the fluid-structure, considering non-compressible streams and elastic structures with nonlinear geometric method. Input stream turbulence for non-uniform fluid modeling and aerodynamic damping of the structure was not considered in this investigation. The comparison is made between numerical outcomes acquired in this work with numerical and empirical estimations. Furthermore, the wind reaction of tall structures with moderately firm footings on homogeneous coarse soil has been examined utilizing two diverse methodologies for showing the impact of base soil framework: (i) Linear approach. (ii) Nonlinear approach. At last, some critical comments about this simulation have additionally been made.

\section{Numerical methods}

\subsection{Numerical model for simulating wind flows}

In the CWE field, wind streams are typically characterized by the accompanying suppositions :

(i) Natural wind streams are considered as an incompressible stream.

(ii) The normal streams of wind are in the turbulent stream zone.

(iii) Wind have steady temperature (isothermal process).

(iv) Gravity are disregarded in the flow stream.

(v) The air is mechanically considered as a Newtonian liquid .

The non-uniform energy equations in the integral frame for a control volume can be as following (ABAQUS (2012)):

$$
\frac{d}{d t} \int_{V} \rho v+\int_{S} \rho v \otimes\left(v-v_{m}\right) \cdot n d S=-\int_{V} \nabla p d V+\int_{S} \tau \cdot n d S+\int_{V} f d V .
$$

Where $\mathrm{V}$ is a desired control volume with surface $\mathrm{S}, \mathrm{n}$ is normal to the outside, $\rho$ is the fluid density, $\mathrm{p}$ is pressure, $\mathrm{v}$ is the speed vector, $\mathrm{v}_{\mathrm{m}}$ is the speed of the mesh, $\mathrm{f}$ is the volume force and $\tau$ is the viscous shear stress. Non-compressibility requires a celenoidal speed field represented as: 
A non-compressible Abaqus/CFD solver for time-dependent subjects, utilizes a advanced second-order mapping strategy with the node-centered discretization of finite element for pressure and cell-centered discretization of finite volume for all other transfer factors, (for example, speed, turbulence). This hybrid approach ensures exact solution and wipes out the likelihood of making counterfeit pressure states, while safeguarding the neighborhood conservation qualities related with customary finite volume strategies .

The ILES (implicit large eddy simulation) turbulence model, depends on the utilization of a partition of length and time scales in turbulent streams and a system that simulates directly solved stream structures and unsolved sub-lattice properties. ILES is a technique for displaying high Reynolds streams that merges computational productivity and simplicity of execution with adaptable predictions and practical estimations. There are no client setups for this turbulent model .

The Abaqus/CFD utilizes an Arbitrary Eulerian-Lagrangian calculation (ALE) and a automated mesh deforming technique that keeps up the mesh's size consistent in the boundary layers. ALE calculations and deformable lattices are consequently enabled for an issue that incorporates a moving boundary characterized by the client or distinguished as a moving boundary in a FSI. To control the movement of the mesh amid simulation, the client is required to decide the proper conditions for the deformation of computational mesh (ABAQUS (2012)).

\subsection{A numerical model for simulating the dynamics of a building}

Tall structures are described as thin structures with low essential frequency (generally under $1 \mathrm{~Hz}$ ). In this way, these structures might be presented to vital displacements along the wind. In this sense, an investigative model appropriate for describing the dynamics of the building must have the accompanying attributes :

(i) The constituents of the building is elastic.

(ii) The energy equilibrium without heat trade (isothermal approach) is assumed .

(iii) The structure might be displaced and rotated; so, a non-linear geometric method is important to describe the mechanical balance .

Volumetric force at a point, $\mathrm{f}$, can be composed as an outer force, $\mathrm{F}$ and a d'Alembert force in the equilibrium equation as :

$$
f=F-\rho \ddot{u}
$$

Where $\rho$ is the density of material and $u$ is the point displacement. The finite element estimation for the equilibrium equation is equivalent to :

$$
M^{N M} \ddot{u}^{M}+I^{N}-P^{N}=0
$$

Where $M^{M N}=\int_{V_{0}} \rho_{0} N^{N} \cdot N^{M} d V_{0}$ is the steady mass matrix, $I^{N}=\int_{V_{0}} \beta^{N}: \sigma d V_{0}$ is the vector of the interior force and $P^{N}=\int_{S} N^{N} \cdot t d S+\int_{V} N^{N} \cdot F d V$ is the vector of outer force. The implicit operators in Abaqus/Standard for the time incorporation of the dynamic issue incorporate the operator characterized by Hilbert, Hugh and Taylor (1977) and the regressive Euler operator (ABAQUS (2012)).

\subsection{A numerical model for simulating the fluid-structure interaction}

The coupling plan assumes a noteworthy part in numerical modelling of the fluid structure interaction (FSI) issue. For FSI examination, mechanical balance and kinematic continuity must be fulfilled on the interface between various physical areas, which are fulfilled utilizing numerical linking methods. linking methods are grouped into either continuous or partitioned, see Felippa et al. (2001) and Zhang et al. (2004), in which the former uses a solitary arrangement of ruling equations to solve the FSI issue, and the latter solve the autonomous arrangement of each sub-area in a successive way. In the CWE field, a flexible modelling is utilized to decide the impact of wind on structures when interaction occurs between fluid forces and mechanical ones. Since the continuous models are improper in working with CWE issues, a partitioned method is utilized as a part of this work .

Abaqus gives interior techniques to solving multiphase domains. This linking strategy is utilized to model fluid structure interaction. Abaqus/Standard can be joined with Abaqus/CFD. In a simulation, the connection between areas is through a typical physical interface region, where the information are traded coordinately between Abaqus/CFD and Abaqus/Standard, for instance, the fluid pressure on the structure (ABAQUS (2012)).

\subsection{Numerical model for soil simulation}

An direct strategy, in which the whole soil-structure framework is modelled in one stage (without the requirement for disintegration into super-structure and sub-structure), can prompt more exact investigation, but the most developed computer programs required in this technique. Since superposition theories are not required, genuine and nonlinear investigation is possible for this situation (see Borja et al. (1994)). So, the 
direct strategy, which is better in demonstrating the complicated nature of soil-structure interaction in dynamic examination, was utilized as a part of this investigation. Abaqus, finite element analysis program was utilized as a part of this investigation to simulate numerical model of soil. This program can analyze complex issues that require huge memory utilizing a direct strategy.

\subsection{Numerical model for simulating interaction of soil-structure}

Contact surfaces have been utilized to join distinctive mechanical properties of the soil and shallow footing, while any separating and slipping of the base soil amid wind action is demonstrated. In Abaqus, contact surfaces can be utilized to show the interface amongst soil and footing amid incitement. To investigate the interaction of soil-structure in this examination, surface-to-surface contact has been characterized so the principle surface is the soil surface and the slave surface is base of footing. Also, the limited slip rule and the surface-to-surface discretization technique were utilized to model the contact. Mechanical properties of contact surfaces that decide the tangent and normal of contact surfaces can influence numerical analysis and ought to be deliberately chosen. Normal contact is a hard contact in an overclosure-pressure connection, where a hard contact implies that no levels of contact pressure are conveyed unless slave nodes correspond with the principle surface. Infiltration is not permitted in any of the bonds, and there is no restriction to the measure of contact pressure that can be transmitted when the contact is created. The hard contact with the pressure- overclosure relationship for applying the bonds is shown by Equation (2.5). In (2.5), P is the contact pressure and $\mathrm{h}$ is the separation between the two contact surfaces.

$$
P \times h=0, P \geq 0 \text { and } h \geq 0 \text {. }
$$

To display the tangent behavior of contact surfaces in the finite element model, the established Coulomb failure condition was utilized (Nguyen et al. (2016)) .

$$
\mu=\tau / \sigma=\tan (\varphi)+c / \sigma .
$$

Where $\mu$ is the friction coefficient, $\tau$ is the shear strength, $\sigma$ is the normal pressure, $\mathrm{c}$ is the cohesion of envelope, and $\varphi$ is the slope of envelope or the interior friction angle. In this simulation, the normal contact coefficient is taken as 1 , and the extreme contact friction coefficient is 0.84 . The number of contact components is 360 .

\section{Numerical results}

\subsection{Structural model}

The standard CAARC building model has been presented as a flat rooftop with a rectangular cross-area and parallel planar walls that does not have other geometric specification. (See Fig. 5). The building model measurements are as the following: height $(\mathrm{H}=180 \mathrm{~m})$; width $(\mathrm{W}=45 \mathrm{~m})$; length $(\mathrm{L}=30 \mathrm{~m})$. The measurements of the model are scaled with a geometric scale of $1 / 250$ to be compared with tunnel experiments of a similar scale in both aero-dynamic and aero-elastic cases. The damping coefficient is $1 \%$. The structure is discretized by three dimensional elastic brick elements of $5 \times 8 \times 25$. The number of nodes and elements is 2220 and 2926, individually. An average density of $160 \mathrm{~kg} / \mathrm{m} 3$ for the entire building is selected, as proposed by Melbourne (1980). The mechanical characteristics of the structure are given in Table 1, whereas the Young modulus is estimated from numerous tests that are utilized to adjust this parameter in terms of dynamic specification expected for the CAARC building. It is expected that the material is isotropic homogeneous .

In wind tunnel studies, the fundamental frequencies of the CAARC building is kept the same in along wind and across wind directions, utilizing the joint base with the same stiffness on both directions. In this FSI analysis, like Braun and Awruch (2009), a rectangular cross-section building is meshed with solid elements that cannot be adjusted to give a similar stiffness in two primary directions. One of the main highlights of this work is the computational demonstrating of the model that is utilized in the aero-elastic simulation as a flexible body, in spite of the standard wind tunnels tests, where hard models are utilized with degree of freedoms isolated from each other .

As indicated by Ryan and Polanko (2008), the damping matrix in the Rayleigh method is a straight combination of mass and stiffness matrix:

$$
[C]=\alpha[M]+\beta[K] .
$$

$[C],[M]$, and $[K]$, respectively, are damping, mass, and stiffness matrix. $\alpha$ and $\beta$ are coefficients that are utilized to define the damping proportion of the model in two modes. Accepting the same damping proportion $(\xi)$ for two modes with frequencies fi and fj, the coefficients of $\alpha$ and $\beta$ models can be taken as after :

$$
\begin{aligned}
& \alpha=\xi \frac{2 f_{i} f_{j}}{f_{i}+f_{j}} . \\
& \beta=\xi \frac{2}{f_{i}+f_{j}} .
\end{aligned}
$$


In this investigation, the damping coefficient of the structure $(\xi=1 \%)$ alongside of coefficients $\alpha=0.1179$ and $\beta=3.47 \mathrm{e}-5$, that is estimated from first and second dynamical modes of the structure (Table 1), was utilized.

\subsection{Wind Model}

The wind is demonstrated utilizing a boundary layer profile given as the power law relation (Fig. 1). The physical properties of the wind are appeared in Table 2, which gives the Reynolds number $R e=156575$. The aero-elastic analysis were carried out in current work, holds a similar Reynolds number in an extensive variety of wind speeds, which is acquired by changing the dynamic viscosity and wind speed values. A computational area mesh that is used for the current work is appeared in Figure 1 along with the corresponding boundary conditions employed for stream variables. The mesh of the wind domain comprises of 497,000 octagonal elements and 519726 nodes .

The turbulent stream field around the CAARC model is solved through the Navier-Stokes equations and the ILES turbulence model. The measurements of the model are scaled with a geometric proportion of 1/250 similar to building model. The wind tunnel blocking proportion is $0.5 \%$, which is sufficiently little to eliminate the impacts of the walls. The direction of the wind is along the X-axis towards the vast building surface. Mesh lattices are generated from the hexahedral prismatic elements with eight nodes in the fluid area. The framework is as isotropic as feasible to get ideal turbulence in every direction. The analysis physical time is $\mathrm{t}=2 \mathrm{~s}$.

Altogether, two mesh lattices (G1 and G2) are being created to check the reliance on the mesh. The quantity of G1 and G2 mesh is $4.97 \times 10^{5}$ and $1.2 \times 10^{6}$ individually. The comparison of these two models demonstrated same outcomes; accordingly, a simpler model was utilized for later investigations.
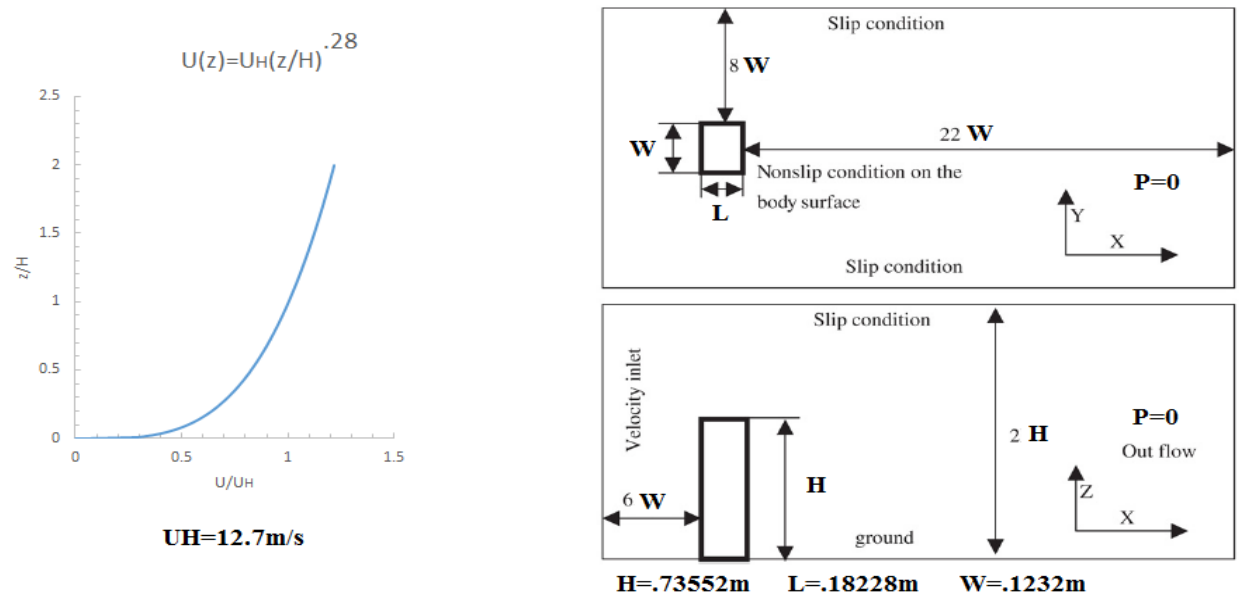

Fig 1: Geometric properties and boundary conditions for the fluid and structural domains

\subsection{Foundation and soil model}

Reinforced concrete footing is a rectangle with $40 \times 50$ m lateral measurements, a height of 3.5 meters and a covered depth of 3.5 meters. Footing with thick plate is sufficiently hard to approve the completely rigid footing assumption in assessing the impacts of SSI. The mass is 16,800 tons and the super-structure mass is 38,880 tons, which is situated on a firm, 50 meter thickness soil, grouped by Iranian standard(2800) as sort 2 and is characterized as a site with a depth of more than 30 meters and the shear wave speed of $375<\mathrm{Vs}<$ $750 \mathrm{~m} / \mathrm{s}$. The soil density is $2160 \mathrm{~kg} / \mathrm{m} 3$, the shear wave speed is $500 \mathrm{~m} / \mathrm{s}$ and the shear strength is $1.8 \mathrm{kPa}$. The properties of this soil have been taken from real examinations in the site and in the research lab. It was expected that the water level is underneath the surface of the bed. Rectangular footing are intended to help the structure against static and dynamic loads, and conform with the engineering design methods to meet the necessities for load bearing limit and peak settlement (Bowles (2001)) .

In the Abaqus program, the soil and footing is meshed with three-dimensional brick elements. If the measure of the element is large, the exchange of the high-frequency segment of wave is troublesome. With a small lattice and higher degrees of freedom, the precision is higher and a computation time is longer. In this way, the proper framework size must be utilized. In this model, the height of the solid elements is $0.21 \mathrm{~m}$ and its greatest size in $x-y$ plane is $.1 \mathrm{~m}$. The number of elements for the SSI framework is 4368. A more exact model with 8636 elements is intended to enhance analysis results. The examination of these two models indicated comparable outcomes; in this manner, the more simple model appeared in Fig. 3 was utilized for next analysis. Figure 8 indicates model segments and a numerical framework for a building with shallow footing. Note that a similar lattice for all models is utilized to make equivalent outcomes for various wind speeds without influencing lattice factors . 
The primary stress created by gravity force influences the contact surface state of the soil-structure interface. If that gravity is not taken in the dynamic investigation, a noteworthy error happens in the analysis. Obviously, when gravity is included, the stress is more prominent than when gravity is excluded in the investigation. In this examination, gravity is taken as a static load in the computation .

Far soil was presented by infinite elements to show energy attracted from the unlimited soil, while lateral displacement was really taken (Fig. 2). Infinite elements, one-sided 8 nodes three-dimensional linear brick (CIN3D8), appeared in Fig. 1 are utilized, but not like other numerical components, these elements have specific direction. Likewise, just linear elastic can be related with infinite elements, however since they are in the far field, the impact of this supposition on the reaction of the super structure under the wind incitement is slight (Cohen et al. 1983). Rigid boundary conditions have been utilized to create bedrock (base of soil network).
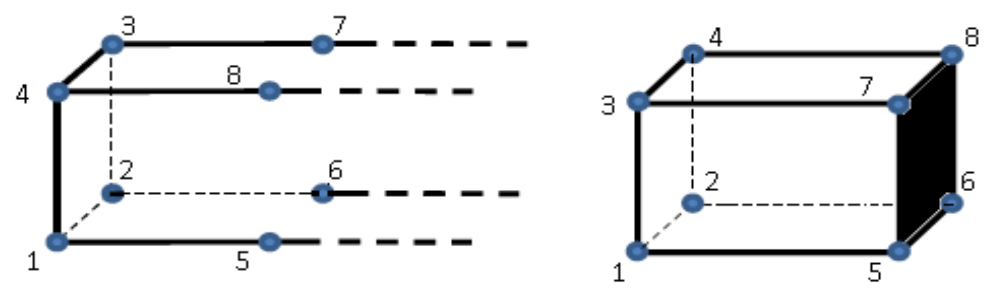

Fig 2: Element types used in the finite element model: infinite elements (CIN3D8) and soil elements (C3D8R)

\section{Verification and Aerodynamic analysis}

The aerodynamic examination was performed as for the wind direction corresponding to the $\mathrm{X}$-axis of the computational area (Fig. 5), and the time step $\Delta \mathrm{t}=0.01$ was selected for the investigation. The helpful aerodynamic parameter utilized as a part of this work to show the aerodynamic action of the CAARC building model are characterized as after :

$$
C_{P i}=\frac{P_{i}-P_{0}}{1 / 2 \rho V_{H}^{2}} .
$$

Where $\rho$ is the fluid mass, $V_{H}$ is the incident wind speed at the building top $\mathrm{H}$. The time mean pressure coefficient $\mathrm{C}_{\mathrm{pi}}$ is gotten from $\mathrm{P}$, the time mean pressure at $\mathrm{i}$, a point in interface surface and $\mathrm{P}_{0}$, the reference pressure .

The mean and r.m.s. estimations of the pressure coefficients on the building border in $\mathrm{Z} / \mathrm{H}=2 / 3$ are displayed in Fig. 3. The result of the numerical model depicted here are compared with experimental and numerical forecasts. Comparisons are made utilizing the outcomes of six tests and numerical works performed by Haung et al. (2007) and Zhang et al. (2015). Experimental tests incorporate six traditional estimations in wind tunnels by the accompanying organizations: University of the City in England; Bristol University in England; Monash University in Australia; and the National Physical Laboratory (NPL) in England; Tong Ji University (TJ) in China; National Aeronautical Establishment (NAE) in Canada. Moreover, two late empirical investigations have been chosen as: Tanaka and Lawen, from the University of Ottawa in Canada, and Goliger and Milford, from the National Building Research Institute (NBRI) in South Africa.

A good correlation is found between the expectations made in this paper for the normal pressure coefficient and the same estimations empirically and numerically from different references. Of course, the distribution of the calculated pressure in the present work is near the empirical expectations of the low turbulence conditions and the outcomes are rational. The agreement between the distinctive estimations performed in $\mathrm{Z} / \mathrm{H}=2 / 3$ is great and, obviously, is high, when $0<\mathrm{X} / \mathrm{L}<1.5$, which is identified as the front of the building. The inverse circumstance is seen in the behind area $(2.5<\mathrm{X} / \mathrm{L}<4)$, in spite of the fact that the expectations for NPL and Huang et al. are low when compared with the rest of the outcomes. At $(1.5<\mathrm{X} / \mathrm{L}<2.5)$, data dispersing is more obvious. But, in this work, the pressure contour is practically identical to different estimations, yet at first with lower estimates than most expectations and from $\mathrm{X}^{\prime} / \mathrm{L}=2$, with higher estimates in respect to different estimations given in Figure 3.

The r.m.s. of pressure distribution results got in this work are practically identical to those given by TJ and Zhang et al. with smooth stream condition when the front surface $(0<\mathrm{X} / \mathrm{L}<1.5)$ is chosen, a noteworthy distinction is found for other forecasts. Comparative dispersion trend can be seen for all estimations made on the lateral surface $(1.5<\mathrm{X} / \mathrm{L}<2.5)$, yet huge contrasts are seen in the r.m.s. of the pressure estimates that are to some extent high and near the predictions of the University of Bristol and Ottawa. The r.m.s. of the pressure contour of this work is in a medium position of data dispersing in the respective intervals. On the 
back surface $(2.5<\mathrm{X} / \mathrm{L}<4)$, the forecasts of the current work are fundamentally the same as the numerical assessment performed at Monash University. But, the distinction between the various results at this interval is vast, particularly if compared with empirical forecasts .

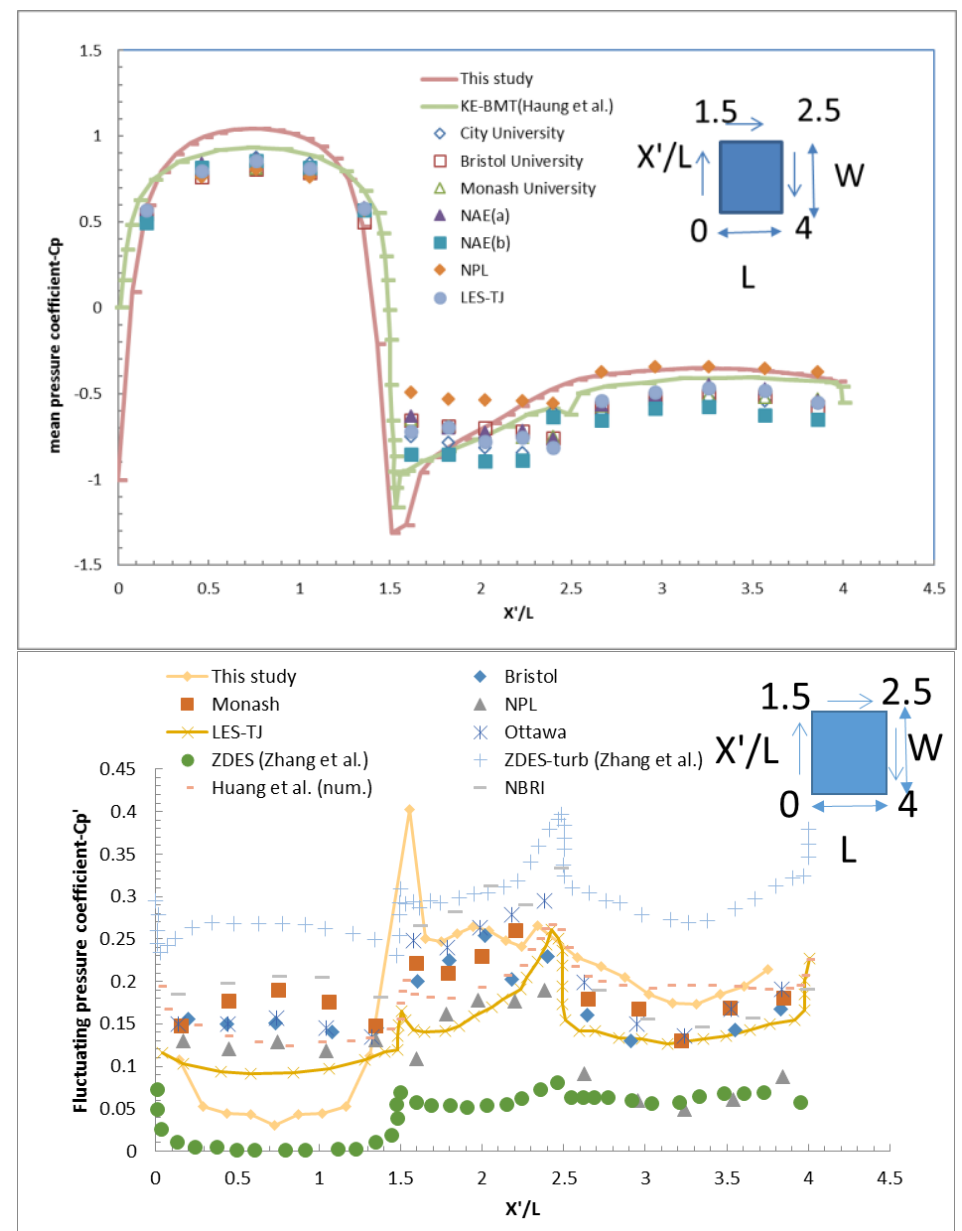

Fig 3: Mean and r.m.s. measurements of pressure coefficients on the structural perimeter at $\mathrm{Z} / \mathrm{H}=2 / 3$ 

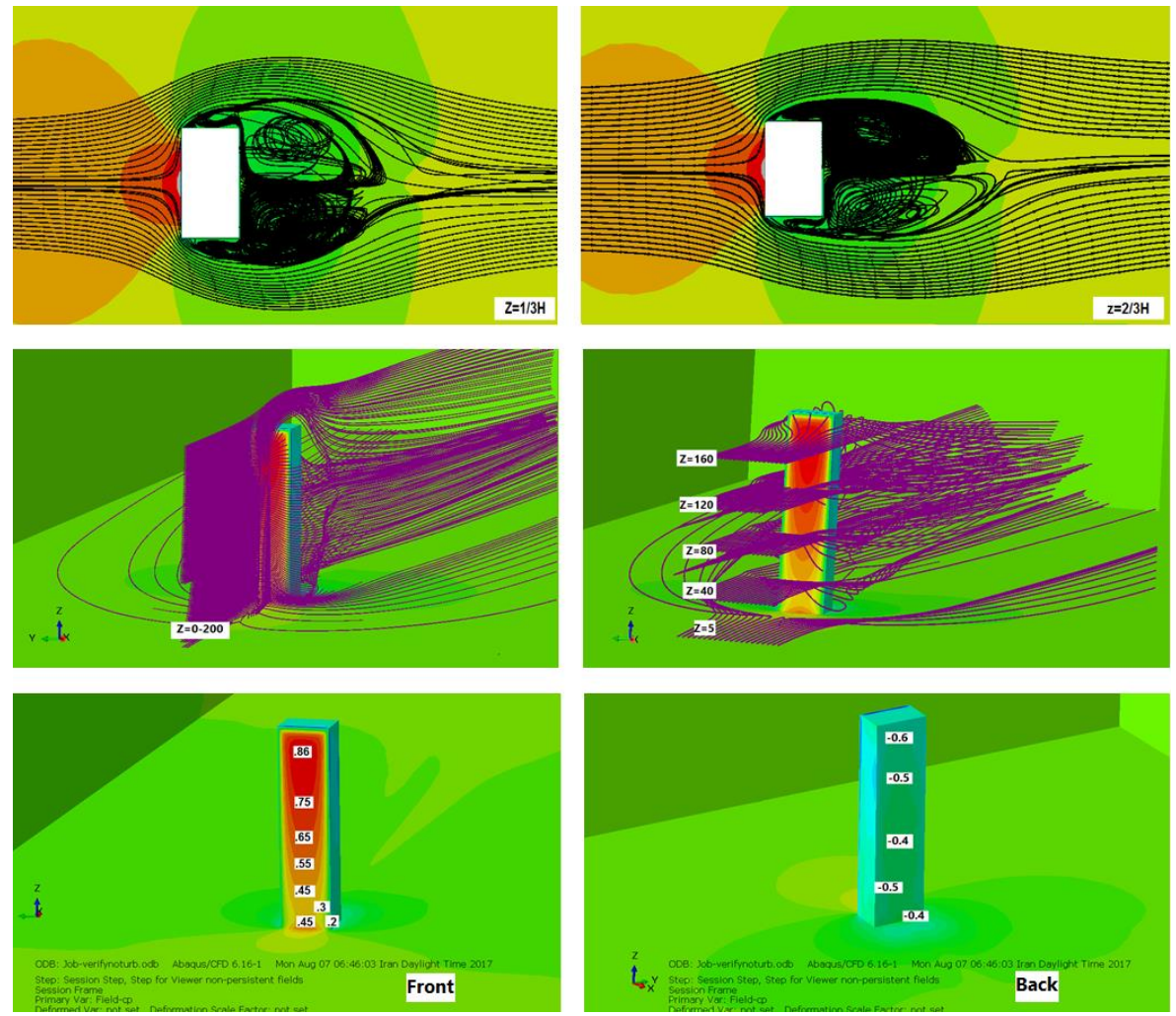

Fig 4: mean pressure fields and flow streamlines on the CAARC building surfaces

The mean stream fields of the simulation appeared in Fig. 4. Where the stream near the building are exhibited on horizontal (X-Y) and vertical (X-Z) surfaces. In this figure, the three-dimensional stream contours are shown along a vertical line at building upstream. A relatively symmetrical stream with two big cyclones in the wake territory is seen in the $X-Y$ surface at $Z / H=1 / 3$. In any case, this phenomenon is not affirmed in $\mathrm{Z} / \mathrm{H}=2 / 3$, where unbalanced cyclones have been made in the building back, as detailed by Haung et al. in their numerical examinations. Huang et al. discovered that the stream field around the building was chiefly affected by the physical properties of the input wind, for example, normal speed and turbulence intensity.

Figure 4 demonstrates the estimations of the normal pressure coefficients of the CAARC building model got in current work on the front and back surfaces. The pressure contour on the front surface is in the great accordance with the estimations reported by Haung et al., albeit numerical outcomes correlate with one of the outcomes introduced by the authors and the outcomes are more dispersed at the back surface, yet an accordance can be confirmed in terms of quantities and the pressure contour position for one of the forecasts.

\section{Aero-elastic Analysis}

The aero-elastic response of the CAARC building model was investigated by analyzing its basic reaction under five wind speeds as indicated by reduced speeds $(\mathrm{VH} / \mathrm{nW}): 2,4,6,8$ and 10 . The physical properties of the structure and fluid sub-frameworks are displayed in Tables 1 and 2, individually. A few numerical assessments are additionally done in terms of the structure damping to analyze the impacts of this parameter on the basic response.

To examine the part of SFSI in the wind-induced reaction of tall structures stated in the past sections, a sequence of analysis on the CAARC building established on stiff footing that lay on coarse thick soil layer as appeared in Fig. 6 has been done. The step time in this work is picked as $\Delta t=0.001 \mathrm{~s}$. The computations perfomed on a supercomputer in the distributed computing center in Amirkabir University. If 90 seconds for every time step is required for G1 configuration, utilizing 16 processors, around 50 hour-processors for 2000 steps is required .

Table 1: Structural Mechanical Properties

\begin{tabular}{lr}
\hline Specific mass- $\rho$ & 160 \\
Natural frequency-n & 0.2 \\
Young modulus-E & $2.3 \times 10^{8}$ \\
Poisson ratio- - & 0.25 \\
Damping ratio- $\zeta$ & $1 \%$ \\
\hline
\end{tabular}


Table 2: fluid Physical Properties

\begin{tabular}{lr}
\hline Specific mass- $\rho$ & 1.25 \\
Dynamic viscosity- $\mu$ & $1.825 \times 10^{-5}$ \\
Volumetric viscosity $-\lambda$ & 0 \\
Reference velocity(Inflow at $Z=180)-\mathrm{V}_{\mathrm{H}}$ & 12.7 \\
Characteristic dimension(Width)-W & 0.18 \\
\hline
\end{tabular}

For the demonstrating of nonlinear behavior of soil masses, the Dracker-Prager failure model is utilized. Progressed Drucker-Prager models are utilized to model frictional materials, which are granule, and show pressure dependent behavior (the material gets more firm when the pressure rises). With a goal to reach a rational scale model, a dynamic similitude between the model and the prototype must be utilized, see Hariss et al. (1999). Dynamic similitude creates conditions in which comparative parts of the model and prototype experience a similar net forces. The example scaling coefficients are displayed in Table 3. Utilizing the geometric size of 1/250, the diameter and depth of the cylindrical model of the soil are determined to be 6 $\mathrm{m}$ and $2 \mathrm{~m}$. Other soil properties in the Dracker-Prager model are appeared in the table 4 after being scaled.

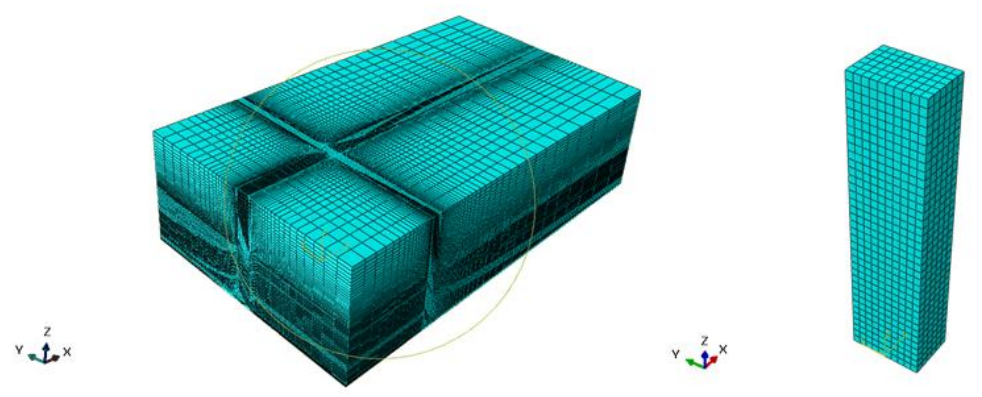

Fig 5: Mesh constructions for the CAARC building and wind flow domains
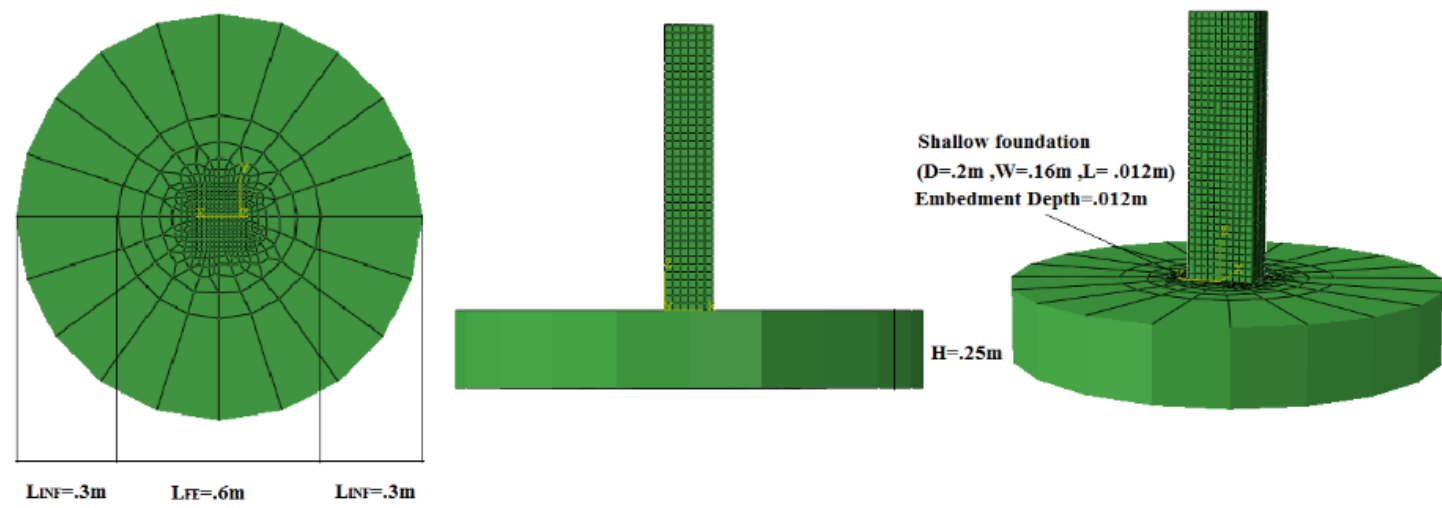

Fig 6: Geometric properties, boundary conditions, mesh configuration of the soil domain

Table 3: Scaling coefficients based on geometric scale factor

\begin{tabular}{llll}
\hline Mass density & 1 & Time & $\lambda^{1 / 2}$ \\
Force & $\lambda^{3}$ & Frequency & $\lambda^{-1 / 2}$ \\
Stiffness & $\lambda^{2}$ & Length & $\lambda$ \\
Modulus & $\lambda$ & Stress & $\lambda$ \\
Acceleration & 1 & Strain & 1 \\
\hline
\end{tabular}

Table 4: Soil properties

\begin{tabular}{lr}
\hline Soil Properties & Value \\
\hline Mass Density & 2160 \\
Poisson's Ratio & 0.3 \\
Shear modulus & 4160000 \\
Angle of Friction & 46.22 \\
Flow Stress Ratio & 0.788
\end{tabular}


Furthermore, the hyperbolic function developed by Prevost and Keane (1990) for the plastic stress-strain curve of soils is utilized to present solidifying in the Dracker-Prager model. This model is characterized as after:

$$
\tau=\tau_{\max } \frac{\gamma}{\gamma_{r}+\gamma} .
$$

Where $\gamma_{\mathrm{r}}=\tau_{\max } / \mathrm{G}_{0}$ is the reference strain (see, Hardin (1972)) and $\tau_{\max }$ is the peak shear stress in the peak shear strain $\gamma_{\max }$ and $\mathrm{G}_{0}$ is the initial shear modulus. Here, $\tau_{\max }$ and $\gamma_{\max }$ values are 1812 and 100 . The elastic strain limit is gotten from the accompanying equation (Oztoprak et al. (2013):

$$
\gamma_{e}=\left(8 \times 10^{-5}\right)\left(\frac{p^{\prime}}{p_{a}}\right)+6 \times 10^{-4}
$$

Where $\mathrm{p}^{\prime}$ is the mean effective pressure and $p_{a}$ is reference environmental pressure and $\gamma_{\mathrm{e}}$ is the limit of the elastic strain that is $46.84 \times 104$. The yield shear stress-plastic shear strain curve utilized here is appeared in Fig. 7 .

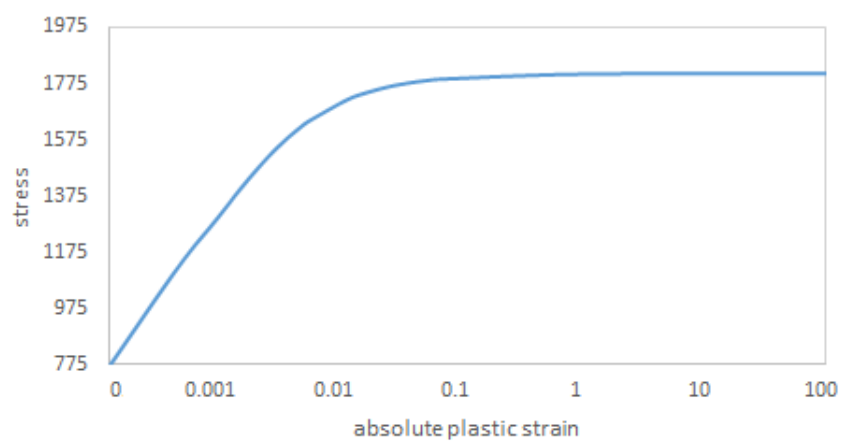

Fig 7: Plastic shear stress - shear strain curve used in this study for hardening of soil

The full numerical program is clarified in Table 5. The acronyms appeared in the first segment of Table 5 are identified with :

(i) Different models of selected soil. Specifically: R for firm soil (without SSI impact); LE for linear elastic reaction; NL for nonlinear reaction .

(ii) Introduction of structure and soil damping through Riley damping. In particular, a D is included when structure and soil damping are brought into the examination, for instance in the LEDO

(iii) Time histories selected for wind loads. In particular, two unique sets are considered, identifying with roughness state of open earth $(\mathrm{O})$ and urban land $(\mathrm{U})$.

Table 5: Simulation program

\begin{tabular}{llll}
\hline Case & Soil Model & Structure Damping & Terrian Condition \\
\hline RO & Rigid & No & Open \\
ROD & Rigid & Yes & Open \\
RU & Rigid & No & Urban \\
RUD & Rigid & Yes & Urban \\
LEO & Elastic & No & Open \\
LEOD & Elastic & Yes & Open \\
NLO & Inelastic & No & Open \\
\hline
\end{tabular}

Table 6 demonstrates the initial three natural frequencies of the firm and linear elastic models (LEs). The initial two modes are totally transitional, while the third one is a torsional.

Table 6: Natural frequencies of the R and LE models

\begin{tabular}{ccc}
\hline Mode & $\begin{array}{c}\text { Natural Frequency-Rigid } \\
\text { Model }\end{array}$ & $\begin{array}{c}\text { Natural Frequency-Elastic } \\
\text { Model }\end{array}$ \\
\hline $1^{\text {st }}$ & 3.161 & 2.784 \\
$2^{\text {nd }}$ & 4.617 & 3.961 \\
$3^{\text {rd }}$ & 16.048 & 15.907 \\
\hline
\end{tabular}




\subsection{Structural Damping Effect}

Of course, the longitudinal displacement amplitudes increase with increasing of speed, which is affirmed for the mean and peak longitudinal displacement (Table 7) .

Table 7: Average, maximum and r.m.s. displacement at the top of the building for RO

\begin{tabular}{llll}
\hline Reduced Velocity & $\overline{\mathrm{x}}$ & $\mathrm{x}_{\max }$ & $\sigma_{\mathrm{x}}$ \\
\hline $\mathrm{V}_{\mathrm{r}}=2$ & $2.12 \mathrm{e}-4$ & $4.62 \mathrm{e}-4$ & $1.66 \mathrm{e}-4$ \\
$\mathrm{~V}_{\mathrm{r}}=4$ & $7.57 \mathrm{e}-4$ & $1.79 \mathrm{e}-3$ & $6.37 \mathrm{e}-4$ \\
$\mathrm{~V}_{\mathrm{r}}=6$ & $1.57 \mathrm{e}-3$ & $3.99 \mathrm{e}-3$ & $1.597 \mathrm{e}-3$ \\
$\mathrm{~V}_{\mathrm{r}}=8$ & $2.6 \mathrm{e}-3$ & $7.28 \mathrm{e}-3$ & $3.08 \mathrm{e}-3$ \\
$\mathrm{~V}_{\mathrm{r}}=10$ & $3.92 \mathrm{e}-3$ & $1.13 \mathrm{e}-2$ & $4.74 \mathrm{e}-3$ \\
\hline
\end{tabular}

Average and r.m.s. of structural reactions normalized with the cross-sectional measurements of the building model are appeared as function of reduced speed $(\mathrm{VH} / \mathrm{nW})$ in Fig. 8. Alongside this, the minimum and maximum estimates are shown for the dispersing of data given by Melbourne that proposed the function for the best fitting with the given data (see the corresponding curve in Fig. 8). The average normalized displacement curve $(\overline{\mathrm{x}} / \mathrm{L})$ got in this paper, in terms of damping, is extremely correlated with the empirical forecasts given by Thepmongkorn et al. at lower speeds. The accordance between the current outcomes and the proposed relation by Melbourne is noteworthy, despite the fact that the curve got from the present work is somewhat higher than the proposed function of Melbourne at lower speeds .

Curve relating to r.m.s. of the normalized displacements in the longitudinal wind $(\sigma \mathrm{x} / \mathrm{L})$ got in the present examination show a rational relationship with the forecasts made by Thepmongkorn et al. considering damping of structure. In the lower part of reduced speeds, estimations for r.m.s. of the wind displacement in this work is higher than the dispersing of data reported by Melbourne. However, current estimations begin to offset additionally from Melbourne's data at $\mathrm{VH} / \mathrm{nW}=4$. But, a comparative trend is seen in estimations for higher reduced speed compared with the peak $\sigma \mathrm{x} / \mathrm{L}$ given by Melbourne. The proposed curve by Melbourne for the $\sigma \mathrm{x} / \mathrm{L}$ data accessible at that period was unreasonable (see the corresponding curve in Figure 8), since today it is notable that r.m.s. of the wind speed reaction varies with reduced speeds by power of approximately three (see, for instance, Refs. 5 and 6). Then, the change in mean reaction by wind speed to power of 2, as proposed by Melbourne, is very rational.

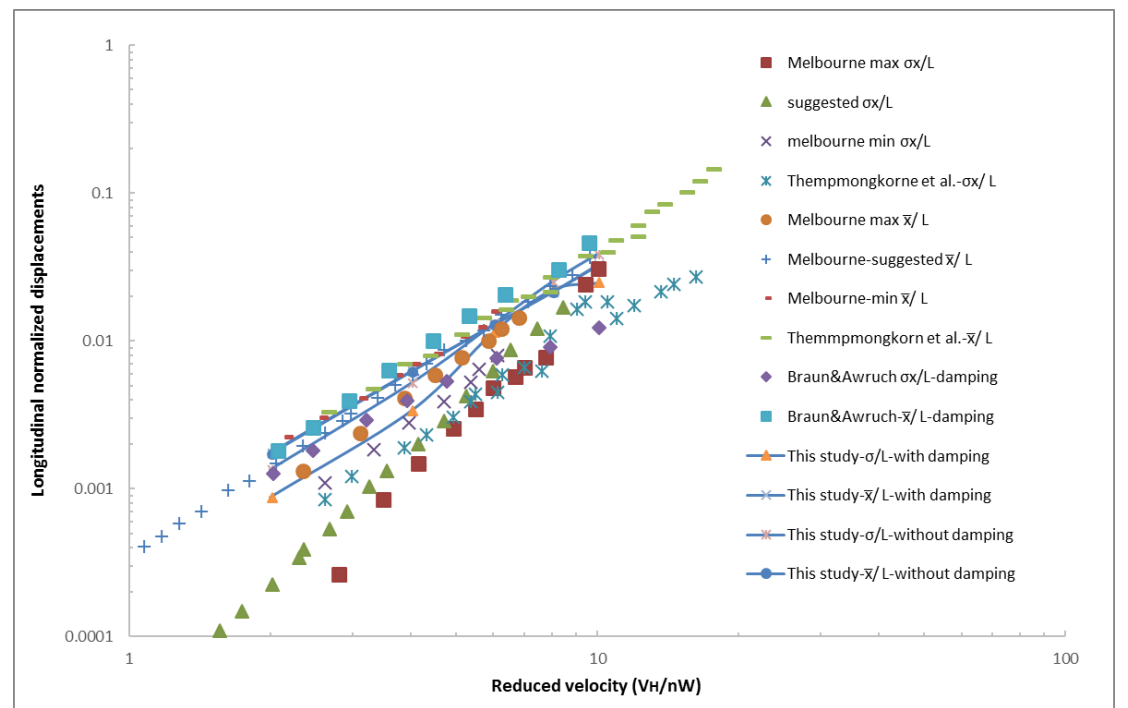

Fig 8: Normalized longitudinal displacements as a function of reduced velocity

Contrasts between empirical outcomes and numerical estimations in this work might be clarified by the accompanying comments: (a) contrary to wind tunnel works where structural reactions in the primary directions of the model are acquired independently without regarding of interconnection between them, the current numerical model represent all vibrational modes altogether; (b) because of the flexibility of the building in the aero-elastic investigation, the relating dynamic reaction can be contrasted with the model of the building in the tests; (c) Wind tunnel tests utilize a similar normal frequency in two principle axis of the model, which is an inconceivable physical assumption when the rectangular models are considered; (d) since 
the structural reaction is roughly corresponding to reduced speed to a power of 2 to 3 , any little change in the wind profile that is input as the boundary condition may have a considerable change accordingly. All modelling performed without structural damping have a noteworthy increment in r.m.s. of reaction in longitudinal wind.
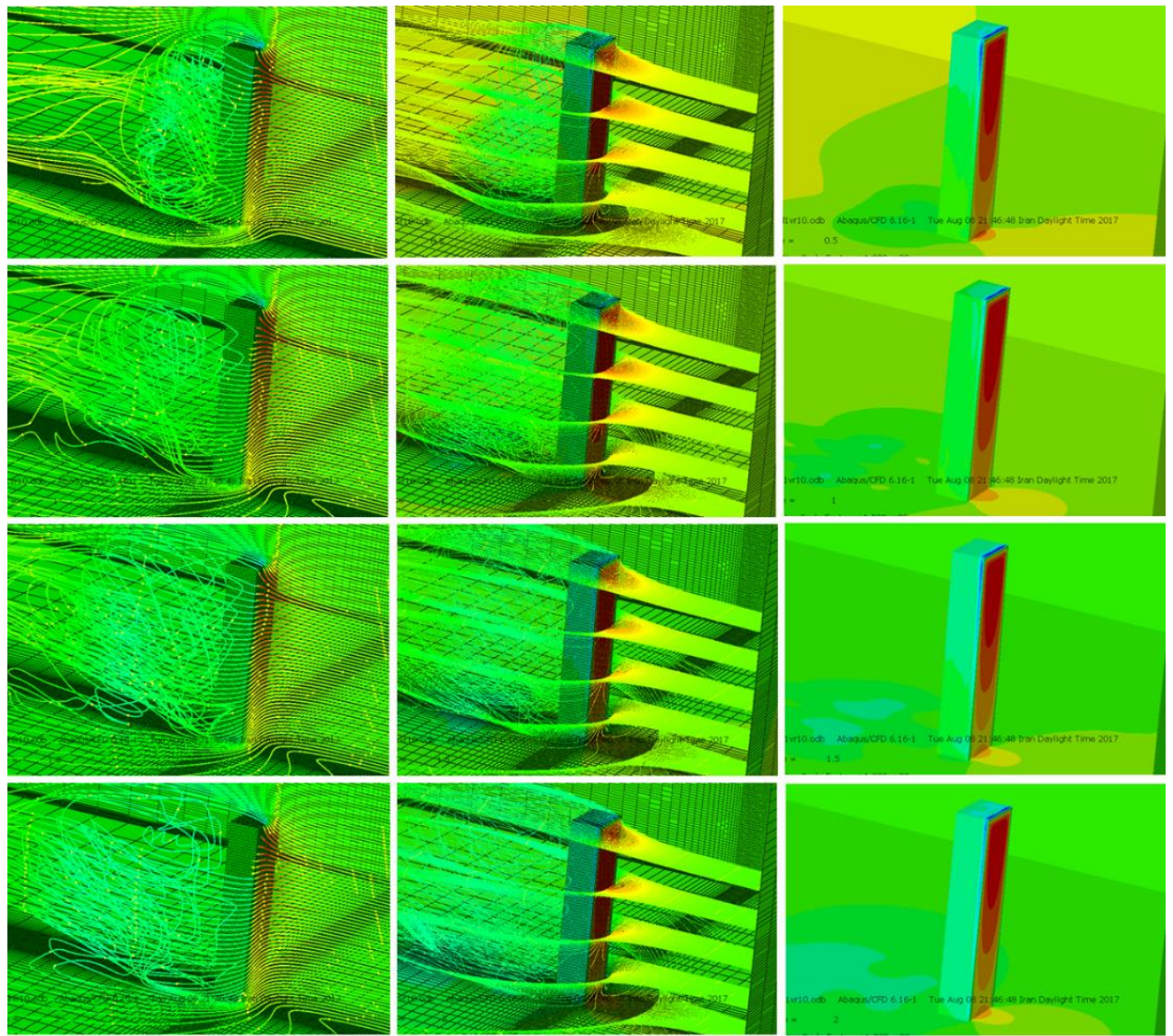

Fig 9: Pressure fields and flow streamlines obtained in the aero-elastic analysis of the CAARC building on $\mathrm{z}=5,40,80,120,160 \mathrm{~m}$ and $\mathrm{y}=0$ at $\mathrm{t}=0.5,1,1.5,2 \mathrm{~s}$

The streamlines and pressure contours got in the present investigation are appeared in Fig. 9. Stream distribution schemes created in the surroundings of tall structures are regenerated for wind streams around the models with boundary layer attributes. An extensive circulation area is made on the land in the front of the building, which is shaped by the extents of the fluid nearby the upstream wall at elevations between [0, $0.7 \mathrm{H}]$, where $\mathrm{H}$ is the building height. These extents are conducted to the land close to the wall, where they move in contrary to the stream direction, and help create horseshoe vortex far from the circulation zone. Then, fluid streams close to the building top come up over the building to cross from the highest point of the building, and afterward they are headed to the back of the building over the circulation zone behind the building, where they are returned close to the ground.

\subsection{SFSI Effects}

Of course, the anticipated mean wind displacement of the LEO case is higher from the RO case because of soil deformability. For NL case, the mean displacement in 1 second is very like LEO case. But, for larger times, the moving mean in a smaller intervals demonstrates a characterized increasing trend. The oscillations amplitudes along the wind from RO to the NL diminish, and the LEO case demonstrates a medium behavior The statistical estimations of the structural reaction history have been extracted. Numerical outcomes were compared with Tepmongkorn et al. (1999) wind tunnel tests, which utilized jointed models for CAARC building. It is also compared with the FSI analysis results of Braun and Awruch (2009) and Melbourne. Fig. 10 demonstrate the mean normalized displacement over the CAARC building top in the longitudinal direction. It can be seen that the mean reactions of the longitudinal wind in the present work are generally in great compliance when comparing with estimations of Thepmongkorn et al. (1999) and Braun and Awruch (2009), however slightly higher than Melbourne. The logarithmic scale demonstrates that the mean reaction is roughly relative to the reduced speed with power of two, as at first exhibited by Melbourne (1980). At a higher reduced speed of $\mathrm{Vr}=10$, the mean displacement along the wind for NL case reaches to roughly $4.8 \% \mathrm{~L}$, that is, $0.8 \% \mathrm{H}$. Amid $\mathrm{Vr}=3-7$, which is the interval of enthusiasm for most applications, the average 
displacement is under $0.2 \% \mathrm{H}$. Likewise, aerodynamic damping $\xi$ a has no impact on the mean along wind reaction .

Normalized r.m.s. of the longitudinal along wind displacement $\sigma \mathrm{x} / \mathrm{D}$ is introduced in Fig. 10. When $\mathrm{Vr}$ is low, $\xi \mathrm{a}$ is low and has little impact on numerical outcomes. The computations without $\xi \mathrm{a}$ assess excessively the estimations of r.m.s. longitudinal wind speed. Contrasts between experimental outcomes and numerical forecasts for NL case is higher than LE case. In addition, normalized r.m.s. of the longitudinal wind $(\sigma \mathrm{x} / \mathrm{L})$ got for LE demonstrate begin to deviate toward Thepmongkorn et al. and Melbourne estimations at $\mathrm{VH} / \mathrm{nW}$ $=4$.

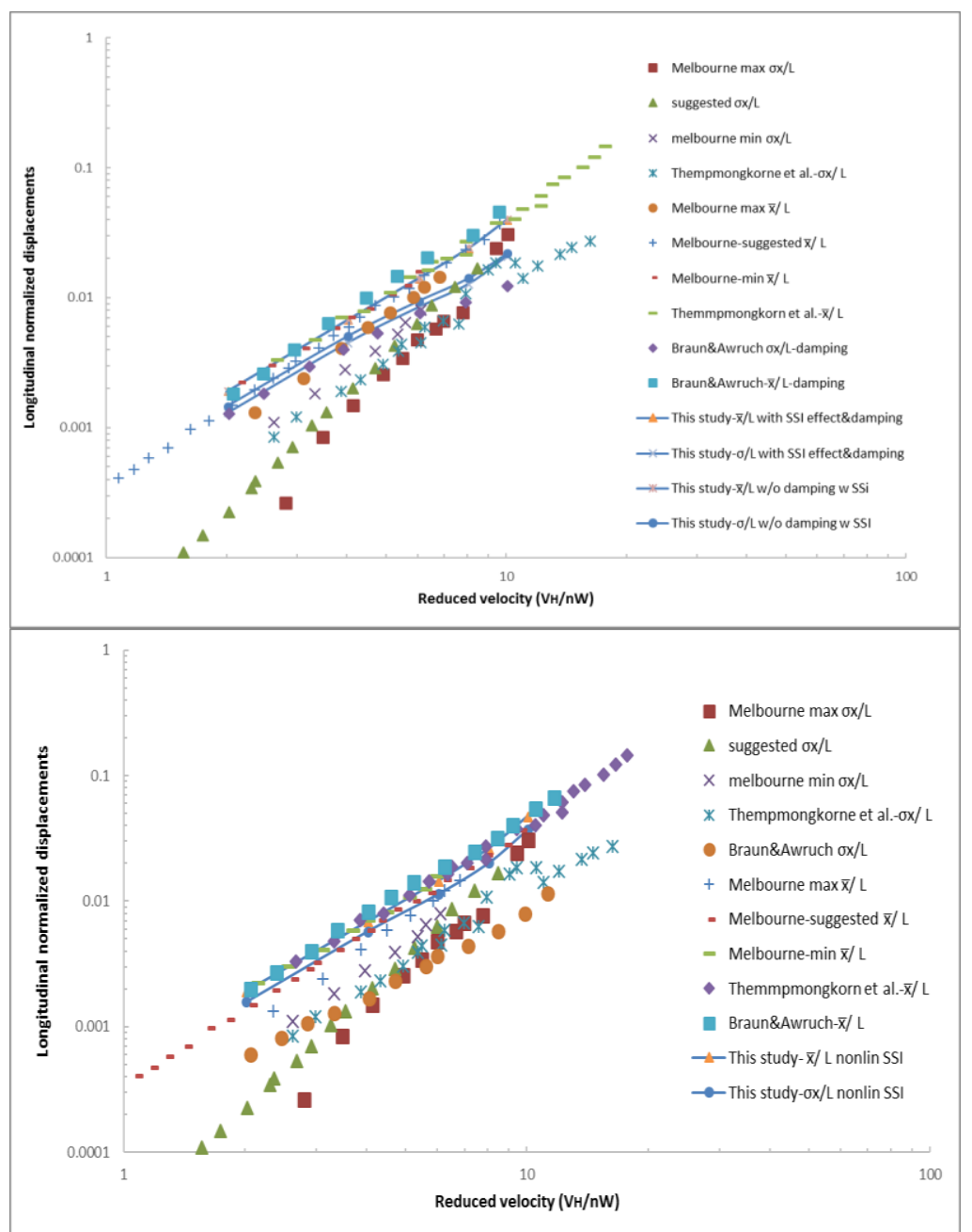

Fig 10: Normalized longitudinal displacements as a function of reduced velocity for LE and NL cases

Fig. 11 demonstrates the moment-rotation response of the soil framework for LE and NL models in open conditions. Of course, the elastic model anticipate a non-dissipative and linear behavior, while the nonlinear model is ready for delivering a reasonable, nonlinear, and hysterical reaction that is described by the amassing of irreversible deflections along it. This is because of that in this path, the wind load have a net positive impact that is added to the oscillations caused by the turbulence. So, the loading cycle is not symmetric. The dynamic aggregation of the base rotation on the $\mathrm{x}-\mathrm{z}$ plane is in charge of increasing the $\mathrm{u}_{\mathrm{x}}$ of the building in the NL case (see Figure 11). 


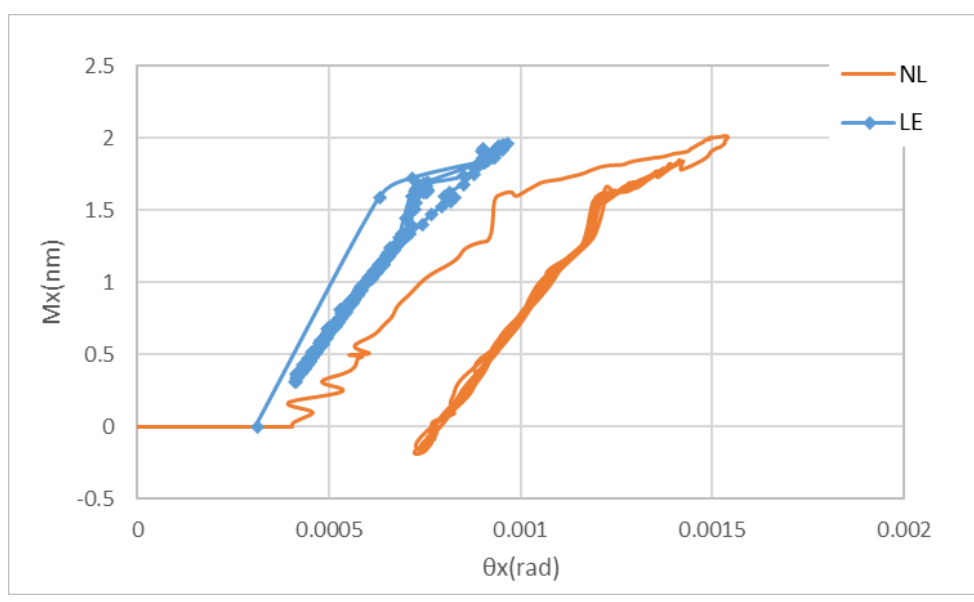

Fig 11: moment- rotation curve for the soil-foundation system of LE and NL models in open ground conditions

Table 8: Absolute maximum values of rocking and torsional rotation

\begin{tabular}{llll}
\hline Case & $\overline{\mathrm{u}}_{\mathrm{x}}(\mathrm{m})$ & $\left|\mathrm{u}_{\mathrm{x}}\right| \max (\mathrm{m})$ & $\sigma_{\mathrm{x}, \max }(\mathrm{m})$ \\
\hline RO & $3.92 \mathrm{E}-03$ & $1.13 \mathrm{E}-02$ & 0.00474 \\
ROD & $4.01 \mathrm{E}-03$ & $9.60 \mathrm{E}-03$ & 0.003046 \\
RU & $4.38 \mathrm{E}-03$ & $1.19 \mathrm{E}-02$ & 0.004818 \\
RUD & $4.41 \mathrm{E}-03$ & $1.12 \mathrm{E}-02$ & 0.004273 \\
LEO & $4.89 \mathrm{E}-03$ & $1.18 \mathrm{E}-02$ & 0.00268 \\
LEOD & $4.86 \mathrm{E}-03$ & $1.16 \mathrm{E}-02$ & 0.002547 \\
NLO & $5.81 \mathrm{E}-3$ & $1.48 \mathrm{E}-2$ & 0.00455 \\
\hline
\end{tabular}

\subsection{Effect of ground conditions}

Table 8 demonstrate the results of every numerical simulations regarding the longitudinal displacements over the structure's top. For two wind conditions considered here, the wind speed is fixed to be the same at the highest point of the building $(12.7 \mathrm{~m} / \mathrm{s})$, but the wind speed profile varies over the height of the building because of various ground roughness. Specifically, the open conditions give higher wind speeds at all levels of the building, so give increased wind loads. Therefore, in all cases as appeared in Table 8, the mean longitudinal wind displacements in urban situations is constantly smaller than the relating displacements in open space .

Table 8 demonstrates the greatest standard deviations in longitudinal wind displacement $\left(\sigma_{\mathrm{xmax}}\right)$ over the building for open and urban conditions. Table 8 demonstrates that the greatest standard deviations of displacements and rotations in the open conditions are higher than those acquired in urban regions. This outcome is because of high wind turbulence that happens in urban territories .

Table 8 also demonstrates the greatest displacement along the wind $\left(\left|\mathbf{u}_{x}\right| \max \right)$ over the building for open and urban conditions. It demonstrates that the reaction in urban zones is generally higher than that found in open terrains, however this differences is influenced by ground condition modelling. Specifically, the reaction of the peak longitudinal wind got in open ground conditions for the LE case is higher than that of the R case. Furthermore, the longitudinal reaction acquired in open conditions is lower for the LE case than the NL case. As already clarified, in some of the analysis, radiation damping, utilizing semi-infinite elements has been presented. In this work, the picked approach for radiation damping is suitable for the computed reactions.

\section{Conclusion}

Some vital comments can be gotten from the outcomes of the numerical model presented here, that can be condensed as after :

1 .According to the aerodynamic examination, the pressure estimations were acquired from the CAARC building analyzing, and the compliance with other test and numerical forecasts was good, when smooth streams or low turbulence were assumed in the investigations. Since r.m.s. forecasts are very susceptible to the input boundary conditions, compliance between r.m.s. of the pressure coefficients of the this work and different works are not noteworthy, in spite of the fact that better relevance for r.m.s. of the pressure coefficient cannot be found in the empirical findings. The pressure field and streamlines around the building acquired in the present work have been very much replicated the stream attributes and test schemes .

2 .The mean normalized displacement along the wind $(\bar{x} / \mathrm{L})$ with structural damping, is numerically assessed, impressively related with experimental forecasts. A compliance between the present outcomes and the test 
estimations when compared with the r.m.s. of the normalized displacements of longitudinal wind $(\sigma x / L)$ are not noticeable, albeit acceptable consistence in lower ranges of reduced speeds is seen here. Of course, structural reactions were acquired without damping leads to higher r.m.s. estimates when comparing with the relating estimations done regarding structural damping .

3 .Inclusion of SSI, significantly affect the forecast of the displacement of the structures. At first, when the soil deformability is included, its amount increments .

4 .The impact of various earth conditions on the structural reaction is impressive regarding displacement. The acquired reaction in urban land, in general, is described by displacements smaller than those in open site .

5. The outcomes give some support to the thought that the regular designing practice tends to over-simplify the issues, assuming a fixed base building. It is vital that such a presumption may dependably be cautious. The perpetual displacement because of the inelastic soil reaction for moderately loading conditions a far from failure of soil may deliver some performance impediments. A quantitative modelling of such impacts requires the inclusion of a constitutive model that can create a nonlinear, irreversible, and path-dependent reaction. In this work, the Dracker-Prager model can be considered as a good compromise between the necessities of good predictive abilities and high computational productivity.

\section{References}

ABAQUS (2012), Abaqus Analysis User's Manual, Minneapolis, Minnesota, Dassault Systemes Simulia Corp., USA.

Blackmore PA (1985), "A comparison of experimental methods for estimating dynamic response of buildings," J Wind Eng Ind Aerodynamics, 18(2): 197-212.

Borja RI, Wu WH, Amies AP and Smith HA (1994), "Nonlinear lateral, rocking and torsional vibration of rigid foundations," J. Geotech. Eng., 120(3): 491-513.

Braun A L, Awruch A M (2009), "Aerodynamic and aeroelastic analyses on the CAARC standard tall building model using numerical simulation," Computers and Structures, 87: 564-581.

Bowles JE (2001), Foundation Analysis and Design, McGraw-Hill International, Editions, 5th Edition, Civil Engineering Series.

Chen L, Letchford CW (2004), "Parametric study on the along-wind response of the CAARC building to downburst in the time domain," J Wind Eng Ind Aerodynamics, 92: 703-24.

Cohen M, and Jennings PC (1983), "Silent boundary methods for transient analysis," Eds. Belytschko T, Hughes TJR, in Computational Methods for Transient Analysis, Elsevier Science Publishers, Amsterdam.

Felippa CA, Park KC, Farhat C (2001), "Partitioned analysis of coupled mechanical systems," Comput Methods Appl Mech Eng, 190: 3247-70.

Goliger AM, Milford RV (1988), "Sensitivity of the CAARC standard building model to geometric scale and turbulence," J Wind Eng. Ind. Aerodynamics, 31(1): 105-23.

Gazetas G (1991), "Foundation vibrations," In: Foundation engineering handbook. Springer, pp. 553-93.

Hirt CW, Ramshaw JD, Stein LR (1978), "Numerical simulation of three-dimensional flow past bluff bodies," Comput. Methods Appl. Mech. Eng., 14(1): 93-124.

Hanson T, Summers D, Wilson CB (1986), "A three-dimensional simulation of wind flow around buildings," Int. J. Numer. Methods Fluids, 6: 113-27.

He J, Song CCS (1997), "A numerical study of wind flow around the TTU building and the roof corner vortex," J Wind Eng Ind Aerodynamics, 67-68: 547-58.

Huang S, Li QS, Xu S (2007), "Numerical evaluation of wind effects on a tall steel building by CFD," $J$ Construct Steel Res, 63: 612-27.

Harte M, Basu B, Nielsen S (2012), "Dynamic analysis of wind turbines including soil structure interaction," Eng. Struct., 45: 509-18.

Halabian AM, El Naggar MH (2002), "Effect of non-linear soil-structure interaction on seismic response of tall slender structures," Soil Dyn. Earthq. Eng., 22: 639-58.

Harris HG, Sabnis GM (1999), Structural modeling and experimental techniques, USA, CRC Press,

Hardin B O, Drnevich V P (1972), "Shear modulus and damping in soils: design equations and curves," J. Geotech. Engng., 98(7): 667-692.

Kwok KCS (1988), "Effect of building shape on wind-induced response of tall buildings," J Wind Eng Ind Aerodynamics, 28: 381-90.

Kausel E (2010), "Early history of soil-structure interaction," Soil Dyn Earthq Eng, 30: 822-32.

Liu M-Y, Chiang W-L, Hwang J-H, Chu C-R (2008), "Wind-induced vibration of high-rise building with tuned mass damper including soil-structure interaction," J Wind Eng Ind Aerodynamics, 96: 1092-102. 
Melbourne WH (1980), "Comparison of measurements on the CAARC standard tall building model in simulated model wind flows," $J$ Wind Eng Ind Aerodynamics, 6(1-2): 73-88.

Murakami S (1993), "Comparison of various turbulence models applied to a bluff body," J Wind Eng Ind Aerodynamics, 46-47: 21-36.

Mochida A , Murakami S, Shoji M, Ishida Y (1993), "Numerical simulation of flow field around Texas tech building by large eddy simulation," $J$ Wind Eng Ind Aerodynamics, 46-47: 455-60.

Nguyen Q V, Fatahi B and Hokmabadi A S (2016), "The effects of foundation size on the seismic performance of buildings considering the soil-foundation-structure interaction," Structural Engineering and Mechanics, 58(6): 1045-1075

Obasaju ED (1992), "Measurement of forces and base overturning moments on the CAARC tall building model in a simulated atmospheric boundary layer," J Wind Eng Ind Aerodynamics, 40:103-26.

Oztoprak S, Bolton M D (2013), "Stiffness of sands through a laboratory test database," Geotechnique, 63(1): $54-70$

Prevost J H, Keane C M (1990), "Shear stress-strain curve generation from simple material parameters," $J$. Geotech. Engrg, 116: 1255-1263.

Ryan KL, Polanco J (2008), "Problems with Rayleigh damping in base-isolated buildings," J. Struct. Eng., 134: $1780-1784$.

Summers DM, Hanson T, Wilson CB (1986), "Validation of a computer simulation of wind flow over a building model," Building Environ, 21(2): 97-111.

Selvam RP (1992), "Computation of pressures on Texas tech building," J Wind Eng Ind Aerodynamics, 43: 1619-27.

Stathopoulos T, Baskaran BA (1996), "Computer simulation of wind environmental conditions around buildings," Eng Struct, 18(11) 876-85.

Tanaka H, Lawen N (1986), "Test on the CAARC standard tall building model with a length scale of 1:1000," J Wind Eng Ind Aerodynamics, 25(1) 15-29.

Thepmongkorn S, Kwok KCS, Lakshmanan N (1999), "A two-degree-of-freedom base hinged aeroelastic (BHA) model for response predictions," J Wind Eng Ind Aerodynamics, 83: 171-81.

Tang UF, Kwok KCS (2004), "Interference excitation mechanisms on a 3DOF aeroelastic CAARC building model," J. Wind Eng. Ind. Aerodynamics, 92: 1299-1314.

Tang Y, Zhao X (2013), "121-Story Shanghai Center Tower foundation re-analysis using a compensated pile foundation theory," Struct. Design Tall Special Build.

Wardlaw RL, Moss GF (1970), "A standard tall building model for the comparison of simulated natural winds in wind tunnels," CAARC, C.C.662m Tech, 25 January.

Whitbread RE (1975), "The measurement of non-steady wind forces on small-scale building models," Proceedings of the fourth IAWE conference. Heathrow, Cambridge University Press, Cambridge, pp. 567574.

Zhang Q, Hisada T (2004), "Studies of the strong coupling and weak coupling methods in FSI analysis," Int J Numer Methods Eng, 60: 2013-29.

Zhang Y, Habashi WG, Khurram RA (2015), "Predicting wind-induced vibrations of high-rise buildings using unsteady CFD and modal analysis," J. Wind Eng. Ind. Aerodyn, 136: 165-179 